\title{
Bimetallic dendrimer-encapsulated nanoparticles as catalysts: a review of the research advances
}

\author{
Xiaohong Peng, ${ }^{* a}$ Qinmin Pan ${ }^{* b}$ and Garry L. Rempel ${ }^{b}$ \\ Received 1st February 2008 \\ First published as an Advance Article on the web 26th June 2008 \\ DOI: $10.1039 / b 716441 f$
}

Bimetallic dendrimer-encapsulated nanoparticles (DENs) are important materials, because they have demonstrated improvement in performance compared to the monometallic DENs in many systems when they are used as catalysts. This tutorial review focuses on the recent research advances in bimetallic DENs with respect to their synthesis, characterization, and applications as catalysts. Bimetallic DENs can be made mainly via three routes: co-complexation, sequential loading, and partial displacement. The research in bimetallic DENs has been significantly promoted by the advancement of characterization instruments. The performances of bimetallic DENs as homogeneous and heterogeneous catalysts in organic synthesis have been compared with both monometallic DENs and their physical mixtures. It is concluded that the synergistic electronic effect in bimetallic nanoparticles enhances their catalytic activities.

\section{Introduction}

Dendrimers are a special class of hyperbranched polymers that emanate from a central core with repetitive branching units, thus having a special molecular structure and controllable size. ${ }^{1}$ A variety of dendrimers with different chemical characteristics have been synthesized in the past 20 years; ${ }^{2,3}$ however, commercial applications of these materials have not yet been well explored. Many of the potential applications include catalysis, ${ }^{4}$ drug delivery, ${ }^{5}$ energy transfer, ${ }^{6}$ molecular recognition, ${ }^{7}$ and papermaking retention, ${ }^{8}$ which are anticipated to be promising due to the three important properties of

${ }^{a}$ Department of Polymer Science and Engineering, South China University of Technology, Guangzhou 510640, P. R. China.

E-mail: pxhpf@scut.edu.cn; Fax: +86 20 87114799;

Tel: + 862087114799

${ }^{b}$ Department of Chemical Engineering, University of Waterloo, Ontario, Waterloo, Canada N2L $3 G 1$.

E-mail: qpan@cape.uwaterloo.ca; Fax: +1 519746 4979;

Tel: + 15198884567 ext. 37111

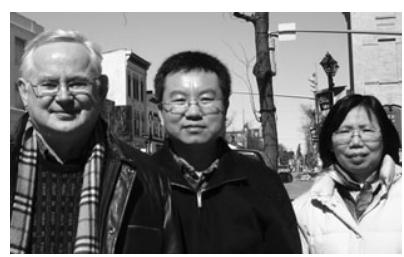

From left to right: Garry L. Rempel, Xiaohong Peng, Qinmin Pan
Xiaohong Peng received his $P h D$ in polymer materials from the South China University of Technology (SCUT) in 1996. He started as an Associate Professor of polymer science at SCUT in 2000. From Mar 2006 to Apr 2007, he worked as a Visiting Scholar at the University of Waterloo with Professor Garry L. Rempel. His current research interests emphasize the preparation of bimetallic nanoparticles as novel catalysts as well as the application in polymeric catalyzed modification.

dendrimers, namely, the large number of end groups, the functionable cores and the nanoporous nature of the interior at higher generations. ${ }^{9}$ Among the main potential applications of dendrimers, catalysis stands out as one of the most promising, because dendrimers offer a unique opportunity of combining the advantages of homogeneous and heterogeneous catalysis whilst yet retaining the well-defined molecular features required for a fully detailed analysis of the catalytic happenings. It is now possible for dendrimers to keep a much better control of the number, shape, and structure of the catalytic sites and their microenvironment.

The emergence of nanotechnology for making metal nanoparticles is providing new opportunities for a potential revolution in the field of catalysis. Dendrimers are particularly attractive hosts for catalytically active metal nanoparticles. The dendrimer-templated formation of nanoparticles can be realized via two methods: the encapsulation of particles in the internal cavity of a dendrimer, and the formation of particles surrounded by dendrimer branches. ${ }^{10-12}$ In the case of amine-

Qinmin Pan graduated with PhD from Zhejiang University in 1987. She is currently an Associate Professor at the Department of Chemical Engineering, University of Waterloo. Her research is in the areas of chemical reaction engineering and polymer materials as well as catalysis techniques.
Garry L. Rempel obtained his PhD in 1968 from the University of British Columbia. He is a Professor and works at the Department of Chemical Engineering, University of Waterloo. He was also a president of the Academy of Science of the Royal Society of Canada in 2001-2002. His research interests are in the fields of catalysis, polymer science, environmental and pollution control. 
terminated poly(amidoamine) (PAMAM), the stronger basic nature of the surface primary amine $\left(\mathrm{p} K_{\mathrm{a}}=9.23\right)$ compared to that of the interior tertiary amine $\left(\mathrm{p} K_{\mathrm{a}}=6.30\right)^{13}$ may lead to the formation of nanoparticles surrounded by a complexation of metal ions with dendrimeric surface amine groups. ${ }^{3,14}$ However, dendrimers with non-complexing functional groups, such as hydroxyl groups ${ }^{15}$ and quaternized amine groups ${ }^{16}$ or by adjusting the solution $\mathrm{pH}$ to selectively protonate the peripherial amine ${ }^{17}$ are generally favored for forming dendrimerencapsulated nanoparticles (DENs). The preparation technique for DENs via dendrimer templates has at least five potential advantages: ${ }^{1,18}$ (1) bearing fairly uniform composition and structure, dendrimer templates themselves yield well-defined nanoparticle replicas; (2) nanoparticles are stabilized by encapsulation within dendrimers, and therefore they do not agglomerate during catalytic reactions; (3) the nanoparticles are retained within the dendrimers primarily by steric effects and therefore a substantial fraction of their surface is unpassivated and available to participate in catalytic reactions; (4) the dendrimer branches can be used as selective gates to control the access of molecules (substrates) to the encapsulated (catalytic) nanoparticles; and (5) the dendrimer periphery can be tailored to control the solubility of the hybrid nanocomposite and used as a handle to facilitate linking to surfaces and other polymers.

In the 1970s, an idea of combining two different metals such us $\mathrm{Au}$ and $\mathrm{Pd}$ in the same nanoparticle to compose a catalyst was proposed. ${ }^{19}$ Thereafter, the idea has been further developed by Toshima's group who used poly( $N$-vinyl-2-pyrrolidone) (PVP) to stabilize 1-3 nm bimetallic PdAu nanoparticles. When such bimetallic nanoparticles were used for the selective partial hydrogenation of 1,3-cyclooctadiene, they exhibited an enhanced catalytic activity compared to the monometallic mixtures of Pd and Au nanoparticles, and extended X-ray absorption fine structure (EXAFS) spectroscopy analysis indicated that the Pd atoms were preferentially on the surface of the particles. However, attempts to make core/shell structures by successive reduction of $\mathrm{Au}$ and $\mathrm{Pd}$ salts led to dispersions containing mixtures of monometallic $\mathrm{Au}$ and Pd nanoparticles. ${ }^{20}$

Following up the prospect of dendrimers as templates for the formation of inorganic nanoparticles, various metal nanoparticles have been successfully prepared. ${ }^{21}$ Although most of the previous studies have been confined to the 'monometallic' nanoparticles, bimetallic nanoparticles composed of two different metal elements have drawn greater interest in the field of catalysis than monometallic ones. This is because bimetallization would make it possible not only to obtain catalysts with improved catalytic activity but also to create new types of catalysts which may not be achieved by monometallic catalysts. ${ }^{22}$ For this reason, this review has focused on the advancement of bimetallic DENs as catalysts, and has emphasized the most recent work with respect to the methods of syntheses, characterization and catalytic applications of bimetallic DENs.

\section{Syntheses of DENs}

The successful syntheses of bimetallic DENs catalysts are the key progress made recently in this field. Scheme 1 is the schematic illustration of the three different approaches for
1. Partial displacement reaction method
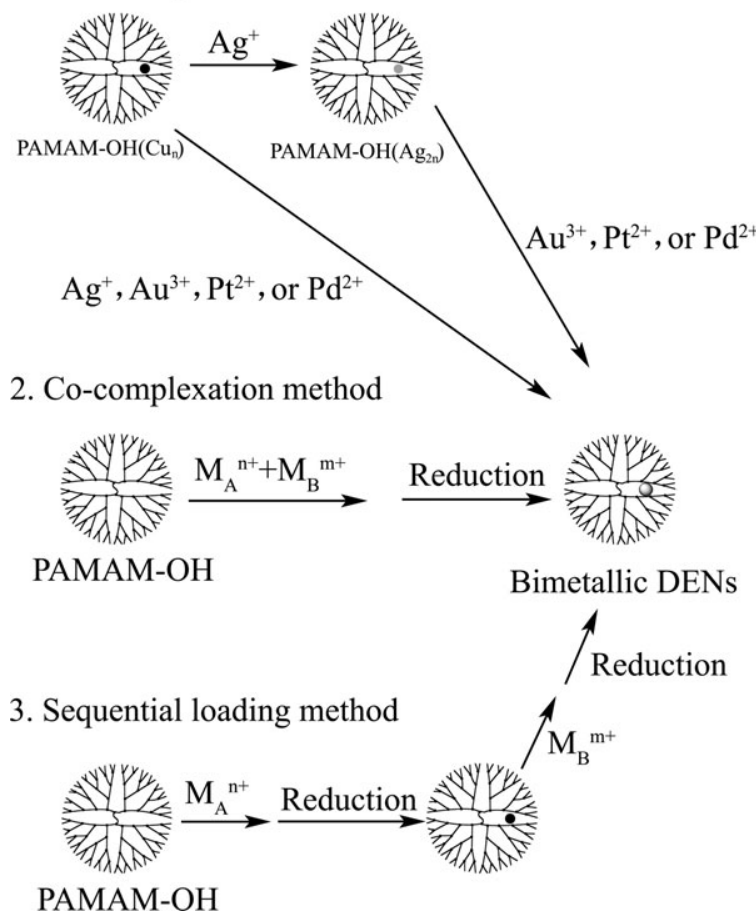

Scheme 1 Schematic representation of three synthetic routes to bimetallic DENs.

preparing such materials: co-complexation, sequential loading, and partial displacement routes. ${ }^{18}$

Bimetallic alloys consisting of $\mathrm{Pd}$ and $\mathrm{Pt}$ had been prepared via the co-complexation route using $\mathrm{K}_{2} \mathrm{PdCl}_{4}$ and $\mathrm{K}_{2} \mathrm{PtCl}_{4}$ complex ions and the G4-OH dendrimer. ${ }^{15,23}$ The resulting PdPt bimetallic DENs were water-soluble, are stable for over one year in solution, and are nearly monodisperse in size. Bright-field, high-resolution transmission electron microscopy (HRTEM) indicated that $\mathrm{G} 4-\mathrm{OH}\left[(\mathrm{Pd})_{30}(\mathrm{Pt})_{10}\right]$ DENs were $2.1 \pm 0.6 \mathrm{~nm}$ in diameter, which is significantly larger than the value of $1.1 \mathrm{~nm}$ calculated for a face-centered cubic packed $\mathrm{PdPt}$ particle. The investigation of monometallic $\mathrm{Pd}$ and $\mathrm{Pt}$ DENs also revealed a discrepancy between the calculated and experimentally determined diameters, ${ }^{24}$ and the rationale of this is still not well understood. It is possibly caused by the steric constraints within the dendrimeric interior that lead to particles having unusual shapes. Single-particle X-ray energy dispersive spectroscopy (EDS) could verify the ratio of $\mathrm{K}_{2} \mathrm{PdCl}_{4}$ and $\mathrm{K}_{2} \mathrm{PtCl}_{4}$ used to prepare the particles. For example, large-area DENs analysis of $\mathrm{G} 4-\mathrm{OH}\left[(\mathrm{Pd})_{30}(\mathrm{Pt})_{10}\right]$ DENs indicated that the atomic percentages are $74 \% \mathrm{Pd}$ and 26\% Pt. Transmission electron microscopy (TEM) micrographs of $\mathrm{G} 5-\mathrm{Q}\left(\mathrm{Ru}_{5} \mathrm{Rh}_{5}\right)$ DENs are shown in Fig. 1. The microscopy demonstrates that the particle size is uniform. The formation of closely monodispersed nanoparticles suggests the effectiveness of dendrimers acting as both nanoreactors for the preparation of nanoparticles and as nanoporous stabilizers for the prevention of aggregation. Specifically, in Fig. 1(b), standardless analysis of the metal composition, bimetallic nanoparticles with a diameter of around $1 \mathrm{~nm}$ were observed. ${ }^{25}$ Scott et al. ${ }^{16}$ prepared PdAu bimetallic DENs and the 

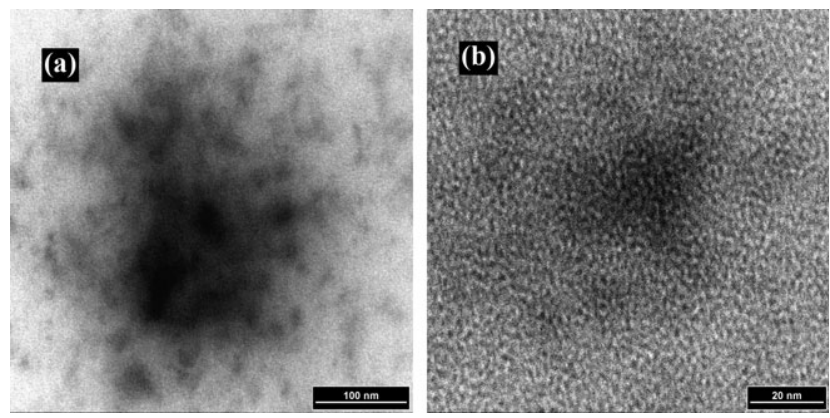

Fig. 1 TEM images of bimetallic G5-Q $\left(\mathrm{Ru}_{5} \mathrm{Rh}_{5}\right)$ nanoparticles. The bimetallic $\mathrm{G} 5-\mathrm{Q}\left(\mathrm{Ru}_{5} \mathrm{Rh}_{5}\right)$ solution: total metal concentration was $0.74 \mathrm{mM}$ and total metal/G5-Q molar ratio $37: 1$. A small amount of the bimetallic $\mathrm{G} 5-\mathrm{Q}\left(\mathrm{Ru}_{5} \mathrm{Rh}_{5}\right)$ solution was placed on a carboncoated copper grid and dried naturally.

technical route is also similar to that for the PtPd bimetallic nanoparticle alloy system. Moreover, Liu et al., ${ }^{26}$ Chung and Rhee, ${ }^{27}$ and Wilson et al. ${ }^{28}$ also reported the syntheses of $\mathrm{PtRu}, \mathrm{PdRh}$, and AuAg bimetallic DENs alloy systems via the co-complexation route as well as the characterizations of these systems.

Although alloy-type bimetallic nanoparticles have been known for a long time, Schmid's group were the first to report the synthesis of core/shell bimetallic nanoparticles, the core/ shell structure being demonstrated using HRTEM and EDS microanalyses. ${ }^{29}$ As a general rule, the sequential loading method is appropriate for the preparation of core/shell bimetallic DENs. For example, Crooks and co-workers had synthesized $[\mathrm{Au}](\mathrm{Pd})$ core/shell nanoparticles by selectively reducing $\mathrm{PdCl}_{4}{ }^{2-}$ onto G6-Q ${ }_{116}\left(\mathrm{Au}_{55}\right)$ seeds using $\mathrm{H}_{2}{ }^{16}$

Representative HRTEM micrograph and particle-size distribution analyses for G6-Q ${ }_{116}\left(\mathrm{Au}_{55}\right)$, G6- $\mathrm{Q}_{116}\left[\mathrm{Au}_{55}\right]\left(\mathrm{Pd}_{95}\right)$, and $\mathrm{G} 6-\mathrm{Q}_{116}\left[\mathrm{Au}_{55}\right]\left(\mathrm{Pd}_{455}\right)$ DENs synthesized by the sequential loading method ${ }^{16}$ showed that the average particle sizes for these materials are $1.3 \pm 0.3,1.8 \pm 0.5$, and $2.3 \pm 0.4 \mathrm{~nm}$, respectively, which are very compatible with the calculated values of 1.2, 1.8, and $2.6 \mathrm{~nm}$, respectively. EDS indicated that all the $[\mathrm{Au}](\mathrm{Pd})$ core/shell nanoparticles were bimetallic, with the compositions similar to the ratio of $\mathrm{PdCl}_{4}{ }^{2-}$ and $\mathrm{Au}^{0}$ used to prepare the DENs. Bimetallic DENs having a Pd core and an $\mathrm{Au}$ shell can also be prepared using Pd DEN seeds and $\mathrm{H}_{2}$ or ascorbic acid to reductively deposit the Au shell. Moreover, Xie et al. ${ }^{30}$ synthesized dendrimer-stabilized $\mathrm{PtCu}$ bimetallic nanoparticles, and attenuated total reflection infrared spectroscopy (ATR-IR) spectra of CO on the bimetallic nanoparticles show a prominent vibrational band around $2171 \mathrm{~cm}^{-1}$, indicative of a terminally adsorbed CO dicarbonyl species on the
$\mathrm{Cu}^{+}$sites. The absence of an IR band for $\mathrm{CO}$ adsorption on $\mathrm{Pt}$ suggests a $\mathrm{Pt}$ core and $\mathrm{Cu}$ shell structure for these $\mathrm{PtCu}$ nanoparticles.

Selective extraction strategies have been used to distinguish the surface compositions of bimetallic DENs. The idea is that [Au](Ag) core/shell DENs (having a Ag oxide layer on their surface) should selectively extract in the presence of an $n$-alkanoic acid and $[\mathrm{Ag}](\mathrm{Au})$ core/shell DENs should selectively extract in the presence of an $n$-alkanethiol. ${ }^{31}$ Table 1 shows a summary of the extraction results for AuAg alloy DENs formed by the co-complexation method as well as for [Au](Ag) and [AuAg alloy](Au) core/shell DENs formed by the sequential loading method. This provided a means for analyzing the composition of the shell. UV-Vis, TEM, and EDS were also used to characterize the bimetallic DENs before and after extraction and has shown that the extraction step did not alter the size or composition of the bimetallic nanoparticles. $^{28}$

However, the large standard potential of the aurate ion $(+1.00 \mathrm{~V} v s$. NHE) makes the preparation of PtAu bimetallic DENs more challenging. ${ }^{32}$ Aqueous mixtures of platinum(II) and gold(III) chloride salts are thermodynamically unstable, and gold(III) can rapidly oxidize the Pt(II) complexes appropriate for binding to dendrimer amine groups. Further, Au(III) is not stable in the presence of hydroxyl-terminated dendrimers, as it can oxidize the hydroxyl groups (forming larger $\mathrm{Au}^{0}$ nanoparticles) in the absence of an additional reducing agent. $^{33}$ To minimize these effects, Chandler's group ${ }^{32}$ prepared $\mathrm{G} 5-\mathrm{OH}\left(\mathrm{Pt}_{16} \mathrm{Au}_{16}\right)$ via the ' $\mathrm{Cu}$ exchange' method: $\mathrm{Cu}$ nanoparticles were initially prepared under $\mathrm{N}_{2}$ inside the $\mathrm{G} 5$ $\mathrm{OH}$ PAMAM dendrimer, and oxygen-free solutions of $\mathrm{K}_{2} \mathrm{PtCl}_{4}$ and $\mathrm{HAuCl}_{4}$ were prepared, mixed, and immediately added to the $\mathrm{Cu}$ nanoparticles (under nitrogen), utilizing the $\mathrm{Cu}^{0}$ nanoparticles as an in situ reducing agent for both Pt and Au. Fig. 2 shows the UV-Vis spectra of G5-OH( $\left(\mathrm{Pt}_{32}\right)$, G5$\mathrm{OH}\left(\mathrm{Au}_{32}\right)$, and $\mathrm{G} 5-\mathrm{OH}\left(\mathrm{Pt}_{16} \mathrm{Au}_{16}\right)$ in solution. The bimetallic $\mathrm{Pt}_{16} \mathrm{Au}_{16}$ spectrum was generally similar to the spectrum of the $\mathrm{Pt}$-dendrimer nanoparticles and the Au-plasmon band around $530 \mathrm{~nm}$ was not present. There was also a very weak shoulder at around $600 \mathrm{~nm}$ that correlates very well with the visible ligand-field transitions in $\mathrm{Cu}(\mathrm{II})$-dendrimer complexes, ${ }^{18}$ which can be due to the presence of larger Au agglomerates.

Preparation of mixed-metal intradendrimer nanoparticles by partial displacement is a straightforward extension of the total displacement approach for forming bimetallic nanoparticles. For example, if less than a stoichiometric amount of single-metal $\mathrm{Ag}^{+}, \mathrm{Au}^{3+}, \mathrm{Pd}^{2+}$, or $\mathrm{Pt}^{2+}$ is added to a G6$\mathrm{OH}\left(\mathrm{Cu}_{n}\right)$ solution, or if less than a stoichiometric amount of $\mathrm{Au}^{3+}, \mathrm{Pd}^{3+}$, or $\mathrm{Pt}^{2+}$ is added to a G6-OH $\left(\mathrm{Ag}_{2 n}\right)$ solution it is

Table 1 Summary of extraction results for $\mathrm{AuAg}$ alloys and $\left[\mathrm{Au}_{55}\right]\left(\mathrm{Ag}_{n}\right)$ and $\left[\mathrm{Au}_{27.5} \mathrm{Ag}_{27.5}\right]\left(\mathrm{Au}_{n}\right)$ core/shell DENs. Reprinted with permission from ref. 28. Copyright 2005 American Chemical Society

\begin{tabular}{llll}
\hline Extractant/DEN & $\mathrm{RSH} / \mathrm{BH}_{4}{ }^{-}$hexane & RCOOH hexane & ${\mathrm{RCOOH} / \mathrm{BH}_{4}{ }^{-} \text {hexane }}$ \\
\hline $\mathrm{Au}$ & Yes & No & No \\
$\mathrm{Au}_{n} \mathrm{Ag}_{55-n}$ & Yes & Yes & No \\
{$\left[\mathrm{Au}_{55}\right]\left(\mathrm{Ag}_{n}\right)$} & Yes & Yes & No \\
{$\left[\mathrm{AuAg}_{55}\left(\mathrm{Au}_{n}\right)\right.$} & Yes & No & No \\
${ }^{a} \mathrm{No}$ extraction for $n=41$ or 55. & & & \\
\hline
\end{tabular}




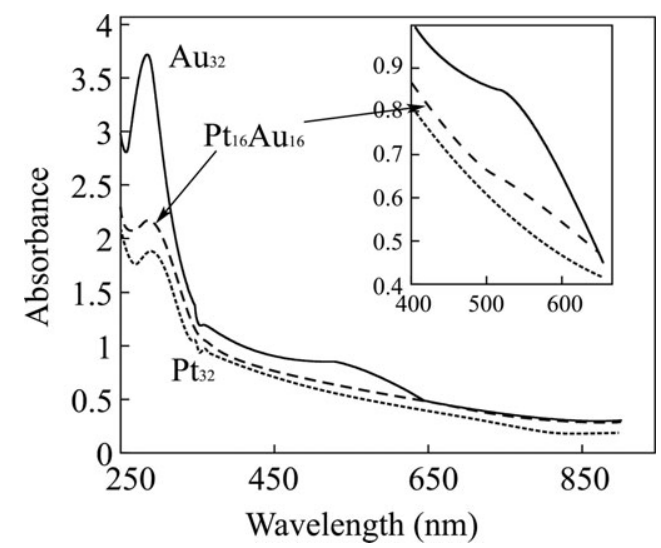

Fig. $2 \mathrm{UV}-\mathrm{V}$ is spectra for $\mathrm{Pt}_{32}(\cdots), \mathrm{Au}_{32}(-)$, and $\mathrm{Pt}_{16} \mathrm{Au}_{16}(--)$ dendrimer-stabilized nanoparticles in solution. Reprinted with permission from ref. 32. Copyright 2004 American Chemical Society.

possible to form $\mathrm{AgCu}, \mathrm{AuCu}(\mathrm{AuAg}), \mathrm{PdCu}(\mathrm{PdAg})$, or $\mathrm{PtCu}$ (PtAg) bimetallic DENs, respectively. ${ }^{18,34}$

In a summary, the major advantage of dendrimer-stabilized bimetallic catalysts is that such catalysts facilitate compositional and structural control greater than compared to traditionally prepared bimetallic catalysts. ${ }^{35}$ The major research regarding bimetallic DENs is summarized in Table 2.

\section{Characterizations of DENs}

The advancement of DEN technology relies extensively on the progress in nanotechnology-related instrumentation analysis. It has been fairly well observed that one's knowledge of the mechanisms of both the formation of DENs and their roles in catalytic reactions is improved by understanding the relationship of composition-structure-function, ${ }^{29,36,37}$ because most of the catalytic reactions are compositionally- and structurally-sensitive. Hence methods to gain more insight into composition-structure aspects are highly desirable.

The electron and atomic force microscopy techniques, such as HRTEM and atomic force microscopy (AFM), can provide qualitative understanding of the structure and morphology of DENs. For example, the HRTEM method enables one to distinguish core/shell structure on the basis of observing different lattice spacing. On the other hand, AFM provides a vertical height measurement that complements the lateral dimension measurement from HRTEM.

X-Ray methods are widely used in a variety of structural and compositional analyses of DENs. X-Ray methods have characterized mainly bimetallic nanoparticles and include X-ray diffraction (XRD), X-ray photoelectron spectroscopy (XPS), EDS and EXAFS etc. The commonly available XRD technique for structural analysis of bimetallic DENs may not provide real structure information. It lacks the ability to identify short-range ordering and periodicities on single crystals or polycrystals; therefore, the conclusions about the structure of DENs cannot be simply drawn from XRD. XPS is a surface-sensitive technique, and it is more suitable for looking at the surface behavior of DENs and synergistic effects. EDS can examine the variations of bimetallic composition of DENs; in particular, it can be possible to determine exactly the bimetallic composition of DENs in the range of around $2 \mathrm{~nm}$ in size assisted by scanning transmission electron microscopy (STEM) microanalysis. ${ }^{15}$

The selective extraction method is a new tool for characterizing the chemical compositions and structures of DENs in the size range of around $2 \mathrm{~nm}$. This is also the only method that has demonstrated effectiveness for distinguishing between core/shell and alloy nanoparticles in this size range. ${ }^{28,38}$ The selective extraction strategy may have potential use for the purification of bimetallic nanoparticles. It can be anticipated that under certain conditions alloy nanoparticles may be efficiently separated from core/shell particles or from monometallic nanoparticles that may have formed during the reduction step.

In addition to the above-described methods and instruments, UV-Vis and ATR-IR are also important instrumentations for characterizing the bimetallic structure of DENs. More information with respect to the characterization techniques is summarized in Table 3.

\section{Applications in catalysis}

Bimetallic DENs used as catalysts have found many applications, and the research arena has now progressed beyond the synthesis of nanoparticles. As one might expect, the primary application for metallic nanoparticles includes two different types of catalysis: homogeneous and heterogeneous. Crooks and co-workers have previously distinguished the two by referring to DENs dissolved in solution as homogeneous catalysts, and those attached to a support as heterogeneous ones; we shall also use the same convention for bimetallic catalysis. ${ }^{31}$ Catalysis with bimetallic nanoparticles prepared via dendrimer template, in particular the very active oxidesupported ones, is now an expanding area, and a number of new catalytic systems for various reactions, such as catalyzed hydrogenation, $\mathrm{CO}$ oxidation, and electrocatalytic $\mathrm{O}_{2}$ reduction, are now being explored. Here the representative applications are reviewed.

\section{Homogeneous catalysts}

More recent investigations have shown that bimetallic DENs were efficient catalysts for the hydrogenation of unsaturated substrates. Crooks and co-worker ${ }^{15}$ measured the turnover frequency (TOF) for the hydrogenation of allyl alcohol in water using $\mathrm{G} 4-\mathrm{OH}\left[(\mathrm{Pd})_{x}(\mathrm{Pt})_{40-x}\right]$ DENs at various atomic ratios of $\mathrm{Pd}$ and $\mathrm{Pt}$ (Fig. 3). The results showed that their ability to hydrogenate allyl alcohol was at higher rates than physical mixtures of monometallic DENs with equal composition. In their optimal composition, these bimetallic composites were more active than Pd- or Pt-only DENs. Such an enhancement observed at PdPt bimetallic nanoparticles of 1-2 $\mathrm{nm}$ in diameter was believed to be due to synergistic electronic (ligand) effects. ${ }^{39}$ The similar experimental results also appeared in the hydrogenation of allyl alcohol when the PdAu bimetallic DEN alloys were used as catalysts, ${ }^{16}$ and the maximal enhancement in the catalytic effect was observed for PdAu alloys at $70 \mathrm{~mol} \% \mathrm{Pd}$. This also was indicative of a synergistic interaction between the $\mathrm{Au}$ and $\mathrm{Pd}$ atoms. The high activity of PdAu bimetallic nanoparticles can be ascribed 
Table 2 Summary of the bimetallic DENs as catalysts

\begin{tabular}{|c|c|c|c|c|c|c|c|}
\hline $\begin{array}{l}\text { Metal } \\
\text { system }\end{array}$ & $\begin{array}{l}\text { Synthetic } \\
\text { route }^{a}\end{array}$ & $\begin{array}{l}\text { Composition } \\
\text { of DENs }\end{array}$ & $\begin{array}{l}\text { Structure } \\
\text { of DENs }\end{array}$ & $\begin{array}{l}\text { Average } \\
\text { diameter/nm }\end{array}$ & $\begin{array}{l}\text { Catalyzed } \\
\text { reaction }\end{array}$ & Property & Ref. \\
\hline$\overline{R u R h}$ & $\mathrm{C}$ & $\mathrm{G} 5-\mathrm{Q}\left(\mathrm{Ru}_{x} \mathrm{Rh}_{y}\right)$ & Alloy & ca. 1.0 & $\begin{array}{l}\text { Hydrosilylation } \\
\text { Hydrogenation }^{c}\end{array}$ & $>98.8 \%^{b}$ & 25 \\
\hline \multirow[t]{3}{*}{$\mathrm{PdAu}$} & $\mathrm{C}$ & G6-Q ${ }_{116}\left(\mathrm{Pd}_{n} \mathrm{Au}_{150-n}\right)$ & Alloy & ca. 1.8 & Allyl alcohol & $70-200 \%(\mathrm{~m})$ & 16 \\
\hline & $\mathrm{S}$ & $\mathrm{G} 6-\mathrm{Q}_{116}\left[\mathrm{Au}_{55}\right]\left(\mathrm{Pd}_{n}\right)$ & Core/shell & $1.8-2.3$ & Allyl alcohol & $30-38 \%(\mathrm{Pd})$ & 16 \\
\hline & $\mathrm{S}$ & G6-OH[ $\left.\mathrm{Pd}_{55}\right]\left(\mathrm{Au}_{n}\right)$ & Core/shell & $2.4-2.9$ & Allyl alcohol & Precipitation & 16 \\
\hline $\mathrm{PdPt}$ & $\mathrm{C}$ & $\mathrm{G} 4-\mathrm{OH}\left(\mathrm{Pd}_{x} \mathrm{Pt}_{40-x}\right)$ & Alloy & ca. 2.1 & Allyl alcohol & $30-50 \%(\mathrm{~m})$ & 15 \\
\hline $\mathrm{PdPt}$ & $\mathrm{C}$ & $\mathrm{G} 4-\mathrm{OH}\left(\mathrm{Pd}_{x} \mathrm{Pt}_{y}\right)$ & Alloy & ca. 2.3 & 1,3-Cyclooctadiene & $45-50 \%(\mathrm{~m})^{d}$ & 14,23 \\
\hline PdRh & $\mathrm{C}$ & $\mathrm{G} 4-\mathrm{OH}\left(\mathrm{Pd}_{x} \mathrm{Rh}_{y}\right)$ & Alloy & ca. 2.3 & 1,3-Cyclooctadiene & $75-120 \%(\mathrm{~m})^{d}$ & 14,27 \\
\hline $\mathrm{PdPt}$ & $\mathrm{C}, \mathrm{S}$ & $\mathrm{G} n-\mathrm{OH}\left(\mathrm{Pd}_{x} \mathrm{Pt}_{y}\right)$ & - & - & 3,4-Epoxy-1-butene & Enhanced $^{e}$ & 26 \\
\hline PtRu & $\mathrm{C}, \mathrm{S}$ & $\mathrm{G} n-\mathrm{OH}\left(\mathrm{Pt}_{x} \mathrm{Ru}_{y}\right)$ & - & - & $\begin{array}{l}\text { 3,4-Epoxy-1-butene } \\
\text { Oxidation }\end{array}$ & Enhanced $^{e}$ & 26 \\
\hline $\mathrm{PdAu}$ & $\mathrm{C}$ & $\mathrm{G} 4-\mathrm{NH}_{2}\left(\mathrm{Pd}_{27.5} \mathrm{Au}_{27,5}\right)$ & Alloy & ca. 1.8 & $\mathrm{CO}$ & $35^{\circ} \mathrm{C}(\mathrm{Pd})$ & 17 \\
\hline $\mathrm{PtAu}^{g}$ & TD & $\mathrm{G} 5-\mathrm{OH}\left(\mathrm{Pt}_{16} \mathrm{Au}_{16}\right)$ & Alloy & $<3.0$ & $\mathrm{CO}$ & $2(\mathrm{Pt}), 8.5(\mathrm{c})$ & 32 \\
\hline $\mathrm{PtCu}^{g}$ & $\mathrm{C}$ & $\mathrm{G} 5-\mathrm{OH}\left(\mathrm{Pt}_{23} \mathrm{Cu}_{23}\right)$ & Alloy & $<3.0$ & $\mathrm{CO}$ & $2(\mathrm{Pt})$ & 44 \\
\hline $\mathrm{PtCu}$ & $\mathrm{C}$ & $\mathrm{G} 4-\mathrm{OH}\left[\mathrm{Pt}_{x}\right]\left(\mathrm{Cu}_{y}\right)$ & Core/shell & $<3.0$ & $\begin{array}{l}\mathrm{CO} \\
\text { Reduction }\end{array}$ & - & 30 \\
\hline PdPt & $\mathrm{C}$ & $\mathrm{G} 6-\mathrm{OH}\left(\mathrm{Pd}_{x} \mathrm{Pt}_{y}\right)$ & Alloy & ca. 1.8 & $\mathrm{O}_{2}$ & $2.4(\mathrm{Pt})^{h}$ & 47 \\
\hline PtAu & $\mathrm{E}$ & $\mathrm{G} 4-\mathrm{NH}_{2}\left(\mathrm{Pt}_{x} \mathrm{Au}_{y}\right)$ & Alloy & - & $\begin{array}{l}\mathrm{O}_{2} \\
\text { Application }\end{array}$ & Good & 48 \\
\hline \multirow[t]{3}{*}{$\mathrm{AuAg}$} & $\mathrm{C}$ & $\mathrm{G} 6-\mathrm{OH}\left(\mathrm{Au}_{27.5} \mathrm{Ag}_{27.5}\right)$ & Alloy & ca. 1.5 & No & - & 28 \\
\hline & $\mathrm{S}$ & $\mathrm{G} 6-\mathrm{OH}\left[\mathrm{Au}_{55}\right]\left(\mathrm{Ag}_{n}\right)$ & Core/shell & ca. 1.9 & No & - & 28 \\
\hline & $\mathrm{C}, \mathrm{S}$ & G6-OH[AuAg] $]_{55}\left(\mathrm{Au}_{n}\right)$ & Core/shell & $1.5-2.7$ & No & - & 28 \\
\hline \multirow[t]{2}{*}{$\operatorname{AgM}_{t}^{i}$} & PD & $\mathrm{G} n-\mathrm{OH}\left(\mathrm{Ag}_{x} \mathrm{M}_{t y}\right)$ & Alloy & - & No & - & 18 \\
\hline & PD & $\mathrm{G} n-\mathrm{OH}\left[\mathrm{Ag}_{x}\right]\left(\mathrm{M}_{t y}\right)$ & Core/shell & - & No & - & 18 \\
\hline \multirow[t]{2}{*}{$\mathrm{CuM}_{t}{ }^{i}$} & PD & $\mathrm{G} n-\mathrm{OH}\left(\mathrm{Cu}_{x} \mathrm{M}_{t y}\right)$ & Alloy & - & No & - & 18 \\
\hline & PD & $\mathrm{G} n-\mathrm{OH}\left[\mathrm{Cu}_{x}\right]\left(\mathrm{M}_{t y}\right)$ & Core/shell & - & No & - & 18 \\
\hline \multirow[t]{2}{*}{$\mathrm{CuAg}$} & PD & $\mathrm{G} n-\mathrm{OH}\left(\mathrm{Cu}_{x} \mathrm{Ag}_{y}\right)$ & Alloy & - & No & - & 18 \\
\hline & PD & $\mathrm{G} n-\mathrm{OH}\left[\mathrm{Cu}_{v}\right]\left(\mathrm{Ag}_{v}\right)$ & Core/shell & - & No & - & 18 \\
\hline
\end{tabular}

${ }^{a} \mathrm{C}=$ Co-complexation, $\mathrm{S}=$ Sequential loading, $\mathrm{PD}=$ Partial displacement reaction, $\mathrm{TD}=$ Total displacement reaction, $\mathrm{E}=\mathrm{Electrodeposi-}$ tion. ${ }^{b}$ The conversion of $\mathrm{Si}-\mathrm{H} .{ }^{c}$ Enhanced percentage in turnover frequency compared to the monometallic DENs and their physical mixture (denoted $\mathrm{m}$ ) in brackets. ${ }^{d}$ The selectivity at the complete conversion of 1,3-cyclooctadiene was higher than $99 \% .{ }^{e}$ Bimetallic DENs enhanced the catalytic activity of the selective hydrogenation (in some cases) compared with materials prepared from traditional wet impregnation of metal salts. ${ }^{f} \mathrm{PdAu}$ catalyst prepared using G4-NH$\left(\mathrm{Pd}_{27.5} \mathrm{Au}_{27.5}\right)$ lowered temperature of complete $(100 \%) \mathrm{CO}$ conversion compared to that of Pd catalyst prepared via G4-NH $\mathrm{NH}_{2}\left(\mathrm{Pd}_{55}\right)$ (in $\mathrm{PdAu}$ system), relative rate times of $\mathrm{Pt}_{16} \mathrm{Au}_{16}$ to those of $\mathrm{Pt}_{32}$ and co-metallic $\mathrm{Pt}_{32}+\mathrm{Au}_{32}(\mathrm{denoted} \mathrm{c}$ ) catalysts at $100{ }^{\circ} \mathrm{C}$ (in PtAu system), and relative rate times of $\mathrm{Pt}_{23} \mathrm{Cu}_{23}$ to that of $\mathrm{Pt}_{45}$ catalyst at $60{ }^{\circ} \mathrm{C}$ (in $\mathrm{PtCu}$ system). ${ }^{g} \mathrm{PtAu}$ and $\mathrm{PtCu}$ alloy catalysts were obtained by removing G5-OH using thermolysis treatment. ${ }^{h}$ Relative factor in electrocatalytic activity compared to monometallic Pt DENs in brackets. ${ }^{i} \mathrm{M}_{t}=\mathrm{Au}, \mathrm{Pt}$, and Pd.

to the electronic deficiency of the active surface Pd atoms (required for $\pi$ back-donation from the coordinated olefin) due to electron transfer to the gold atoms. ${ }^{29}$

Core/shell bimetallic nanoparticles have received significant attention lately because they are models for the formation of alloys at the Angstrom scale, they provide a means for systematic investigation of the electronic properties of catalysts, and they use minimum amounts of precious metals. The hydrogenation of allyl alcohol was examined by using G6$\mathrm{Q}_{116}\left[\mathrm{Au}_{55}\right]\left(\mathrm{Pd}_{n}\right)$ core/shell DENs as catalysts. ${ }^{16}$ For nanoparticles with a sufficiently sized Pd shell ( $c a .250$ atoms), TOF values were $30-38 \%$ higher than those obtained with similar Pd-only DENs (Fig. 4). It should be noted that similar enhancements in catalytic hydrogenation of 4-pentenoic acid have been observed with bimetallic $[\mathrm{Au}](\mathrm{Pd})$ nanoparticles stabilized by sodium dodecyl sulfate. ${ }^{40}$

With regard to reactant selectivity, the dendrimer can, in some cases, provide a means for controlling product selectivity via the sterically confined environment within the dendrimer nanoreactor. ${ }^{41}$ In the Pd DEN hydrogenation reaction for structurally-related allylic alcohols, the density of the peripheral groups on the dendrimer surface and the size of the substrate were shown to be determining factors in TOF. ${ }^{31}$ In particular, the greater steric crowding on the dendrimer surface resulted in a lower TOF for the substrate. Although it is rather intuitive that larger substrates would have more difficulty penetrating a higher generation dendrimer's surface, size is not the only factor. In fact, more polar substrates experience a higher selectivity with Pd DENs than less polar substrates, which is due to the interactions of polar substrates with interior amine groups of the dendrimer that enhance the solubility and thus the TOF. ${ }^{1}$ However, the effect of bimetallic nanoparticles on catalytic selectivity is still more important. Chung and Rhee reported that $\mathrm{PdPt}^{23}$ and $\mathrm{PdRh}^{27}$ bimetallic DEN alloys effectively promote the partial hydrogenation of 1,3-cyclooctadiene to cyclooctene, with selectivities higher than $99 \%$ for complete conversion of the diene. The PdRh DENs were reused without loss of catalytic performance, and again, the bimetallic catalysts were more active than physical mixtures of monometallic nanoparticles. Compared to PVPstabilized bimetallic nanoparticles, similar enhancements for the PdAu catalyst system have also been reported. ${ }^{42}$ Furthermore, the PdPt bimetallic DENs with a Pd content of $80 \%$ showed the highest activity, which was 1.4 times higher than Pd DENs. ${ }^{23}$ Similarly, the PVP-stabilized bimetallic PdPt nanoparticles also showed the highest activity with same $\mathrm{Pd}$ 
Table 3 Summary of the key instrumental and chemical methods used for characterization of bimetallic DENs

$\begin{aligned} & \text { Application } \\ & \text { systems }\end{aligned} \quad$ Limitation

Ref.

\begin{tabular}{ll}
\hline Characterization & Main characteristics and functions \\
\hline $\begin{array}{l}\text { Instrument } \\
\text { (HR or S)TEM }\end{array}$ & $\begin{array}{l}\text { Observed the morphology and } \\
\text { size of bimetallic DENs }\end{array}$ \\
& \\
& \\
AFM & \\
UV-Vis & $\begin{array}{l}\text { Provided a vertical height measurement } \\
\text { that complements the lateral dimensional } \\
\text { TEM measurement } \\
\text { Explored the changing law of different } \\
\text { synthesized routes of bimetallic } \\
\text { DENs, and discriminated different } \\
\text { DEN structures }\end{array}$
\end{tabular}

$\mathrm{PtCu}$ alloy

AuAg alloy

$$
\text { elemental composition }
$$

Estimated the possible structure

of bimetallic nanoparticles via

calculating the number of surrounding

atoms of each absorbing metal element

Chemistry

Extraction

method
Analyzed the chemical composition

of shell and the structure of nanoparticles
PdPt alloy

PdRh alloy

PtRu alloy

PdAu alloy

PtAu alloy

AuAg alloy

RuRh alloy

$\mathrm{PtCu}$ alloy

$[\mathrm{Pd}](\mathrm{Au})$ core $/$ shell

$[\mathrm{Au}](\mathrm{Pd})$ core/shell

$[\mathrm{Pt}](\mathrm{Cu})$ core/shell

[Au](Ag) core/shell

[AuAg alloy](Au)

core/shell

$[\mathrm{Pt}](\mathrm{Cu})$ core/shell

PdPt alloy

AuAg alloy

PdRh alloy

PtAu alloy

$\mathrm{PtCu}$ alloy

$\mathrm{RuRh}$ alloy

PdAu alloy

$[\mathrm{Pd}](\mathrm{Au})$ core/shell

$[\mathrm{Au}](\mathrm{Pd})$ core/shell

[Au](Ag) core/shell

[AuAg alloy](Au)

core/shell

PtAu alloy

PtRu alloy

PdPt alloy

$[\mathrm{Pt}](\mathrm{Cu})$ core/shell

PdPt alloy

PtRu alloy

PdRh alloy

PdAu alloy

PtAu alloy

$[\mathrm{Au}](\mathrm{Pd})$ core/shell

$[\mathrm{Pd}](\mathrm{Au})$ core/shell

$[\mathrm{Pt}](\mathrm{Cu})$ core/shell

PdPt alloy

$\mathrm{PtAu}$

$[\mathrm{Pt}](\mathrm{Cu})$ core $/$ shell

$\mathrm{PdAu}$ alloy

Measured to be lateral dimensions as the TEM-based methods provide only

$15,23,47$

the lateral $(x-y)$ dimensions of

nanoparticles on surfaces. It is very

difficult to directly characterize the

bimetallic nanoparticles having sizes

of the order of $2 \mathrm{~nm}$

14,27

16,17

$32^{a}$

28

25

$44^{a}$

16

16

30

May lead to height anomalies in

$30,36^{b}$

tapping-mode AFM measurements

when particle sizes are below about $10 \mathrm{~nm}$

Cannot quantitatively analyze the

composition of bimetallic DENs

14,23

Approximately evaluated the

surface composition

$32^{a}, 48$

There are large standard deviations

when the particles are smaller

than $1.5 \mathrm{~nm}$

Cannot determine the structure

May be difficult to obtain a satisfactory set of absolute values of coordination number

AuAg alloy [Au] $(\mathrm{Ag})$ core/shell [AuAg alloy] $(\mathrm{Au})$

Some DEN core/shell structure

${ }^{a} \mathrm{PtAu}$ and $\mathrm{PtCu}$ alloy catalysts were obtained by removing G5-OH using thermolysis treatment method. ${ }^{b} \mathrm{G} n-\mathrm{OH}(\mathrm{Pt} x) .{ }^{c} \mathrm{PVP}-\mathrm{protected} \mathrm{PdAu}$ bimetallic nanoparticles.

content in the partial hydrogenation of 1,3-cyclooctadiene: their catalytic activity was 2.2 times higher than Pd nanoparticles themselves. ${ }^{42}$ According to Toshima and Yonezawa, ${ }^{42}$ the enhanced catalytic activity of the bimetallic catalyst can be explained by the following: the electronic interaction between two different metals may provide an uneven distribution of electrons and thus make the electron density of one metal greater than another, which may make bimetallic cluster more active than monometallic ones because the substrate having a double bond favors the electron-deficient surface.

For the kinetic trends of the selective hydrogenation of 3,4epoxy-1-butene using dendrimer-derived $\operatorname{PtX}(\mathrm{X}=\mathrm{Ru}, \mathrm{Pd})$ 


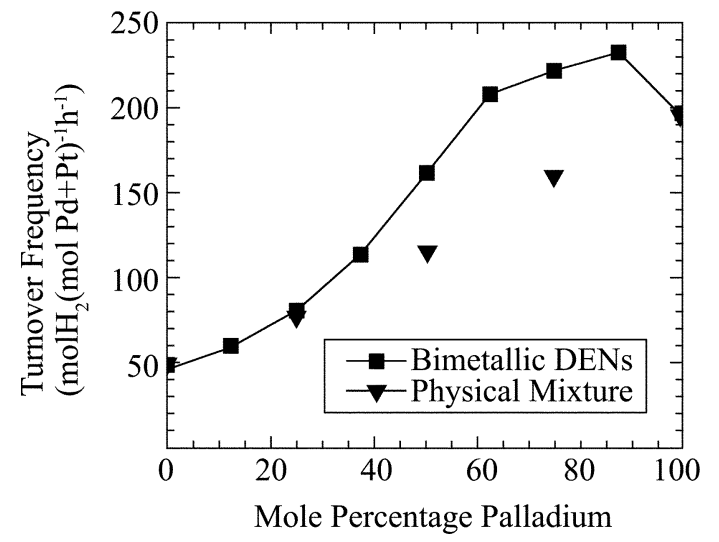

Fig. 3 Plot of turnover frequency (TOF) vs. the $\mathrm{mol} \%$ of $\mathrm{PdCl}_{4}{ }^{2-}$ used to prepare the DENs. The filled squares indicate the results for bimetallic nanoparticles and the filled triangles are for physical mixtures of dendrimers containing either only Pt or only Pd. Reaction conditions: [allyl alcohol] $=200 \mathrm{mM},[\mathrm{Pd}+\mathrm{Pt}]=0.095 \mathrm{mM}$, substrate : metal ratio $=2100: 1, T=19{ }^{\circ} \mathrm{C}$. Reprinted with permission from ref. 15. Copyright 2003 American Chemical Society.

bimetallic catalysts, this also showed an enhanced catalytic behavior (in some cases) compared with catalysts prepared from traditional wet impregnation of metal salts. ${ }^{26}$ It has been found that, at room temperature, G5-Q $\left(\mathrm{Ru}_{5} \mathrm{Rh}_{5}\right) \mathrm{DEN}$ could be used for the regioselective catalysis reaction of poly(methylhydro)siloxane to poly(methylhexyl)siloxane with 1-hexene (see Fig. 5). The G5-Q $\left(\mathrm{Ru}_{5} \mathrm{Rh}_{5}\right)$-catalyzed kinetics displayed a higher efficiency and selectivity of hydrosilylation by FTIR quantitative measurements, and NMR analyses also identified the results. ${ }^{25}$

\section{Heterogeneous catalysts}

Homogeneous catalysis using bimetallic DENs has demonstrated the advantages of both higher catalytic activity and selective catalytic behavior. However, the size-selective catalysis and the absence of solvent may restrict the applications of DENs in catalyzing larger substrate and gas-phase reactant reactions. Heterogeneous catalysis of dendrimer-templated supported bimetallic nanoparticles can overcome these disadvantages. Furthermore, heterogeneous catalysis can also facilitate catalyst separation and reuse. ${ }^{1}$ Heterogeneous catalysis utilizing DENs involves immobilizing them on some kind of solid support such as gold, silica, and titania surfaces or a

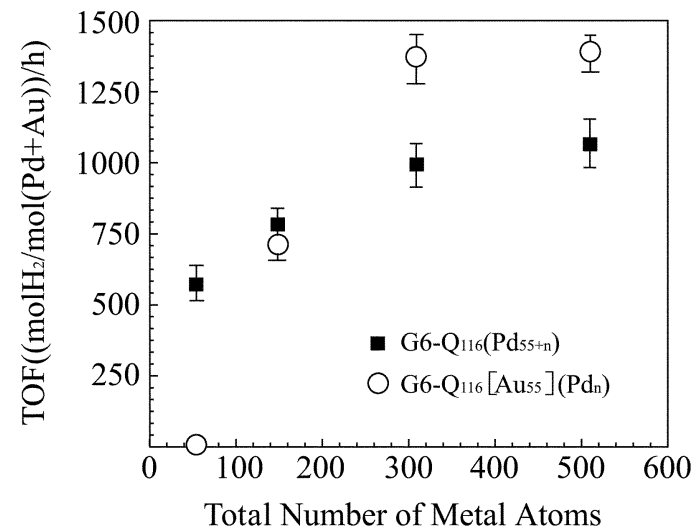

Fig. 4 Turnover frequencies (TOFs) for the hydrogenation of allyl alcohol using G6- $\mathrm{Q}_{116}\left(\mathrm{Pd}_{55+n}\right)$ and $\mathrm{G} 6-\mathrm{Q}_{116}\left[\mathrm{Au}_{55}\right]\left(\mathrm{Pd}_{n}\right)$, which was prepared using the sequential loading method, for $n=0,95,255,455$. Conditions: $22^{\circ} \mathrm{C}$, substrate $:$ metal $=3300: 1,[\mathrm{Pd}+\mathrm{Au}]=150 \mu \mathrm{M}$. TOF data for Pd-only DENs ( $\boldsymbol{\square})$, data for the bimetallic DENs ( $\bigcirc$ ). Reprinted with permission from ref. 16. Copyright 2004 American Chemical Society.

polymer matrix. The principal advantage of using dendrimers for this application can be the size regularity and compositional fidelity of the original nanoparticles, and dispersed nanoparticles with minimal post-aggregation. ${ }^{43}$ Most frequently, surface chemisorption is accomplished through the strong interaction of many surfaces with pendant $-\mathrm{NH}_{2}$ and -OH groups, as featured in commercially-available PAMAM or poly(propyleneimine) (PPI) structure. When an appropriate solvent is present, the supported or immobilized DENs can also be active catalysts or electrocatalysts. ${ }^{31}$ In the absence of a solvent, however, supported intact DENs are inactive catalysts and do not bind such gas-phase reactants as CO. Dendrimer removal is a critical step because after being dried the organic dendrimer apparently collapses onto the nanoparticle, poisoning the metal surface. ${ }^{44}$ The supported G5-OH $\left(\mathrm{Pt}_{16} \mathrm{Au}_{16}\right)$ can be 'activated' by heating under oxidizing $\left(\mathrm{O}_{2}\right)$ and/or reducing $\left(\mathrm{H}_{2}\right)$ atmospheres to remove the organic template. ${ }^{32}$ The analysis of FT-IR spectra obtained at different temperatures indicates that the overall PAMAM dendrimer removal occurs in a two-stage process. The first stage involves the decomposition of the dendrimer skeleton and functional groups to form mixed carboxylates on the catalyst surfaces. The second stage is the removal of these dendrimer decomposition products at elevated temperatures. ${ }^{45}$ In general, provided that activation

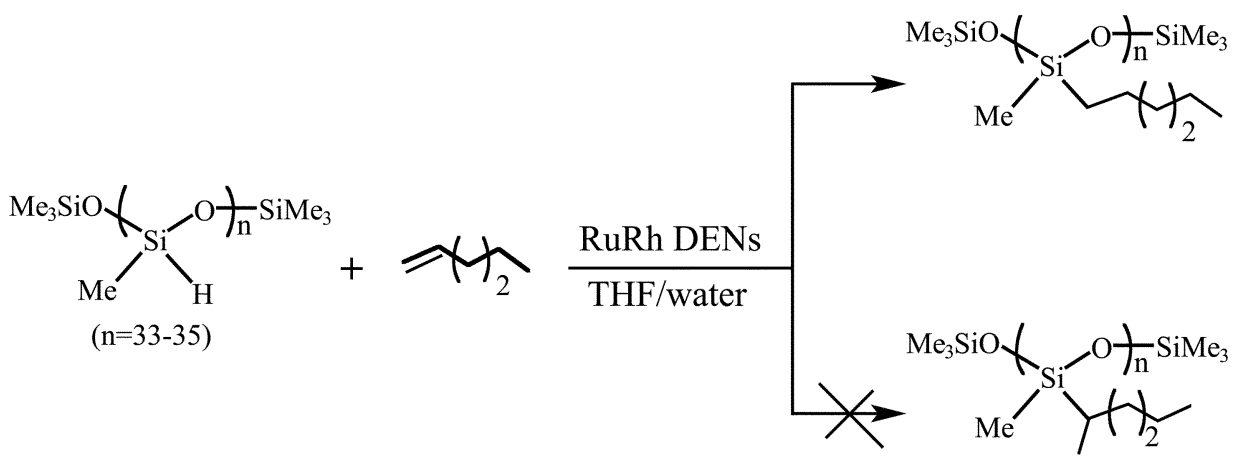

Fig. 5 RuRh DEN-catalyzed regioselective modification of poly(methylhydro)siloxane. 
temperatures are moderate $\left(c a .300{ }^{\circ} \mathrm{C}\right)$, relatively clean nanoparticle surfaces can be prepared without substantial agglomeration, and the resulting $\mathrm{Pt}_{16} \mathrm{Au}_{16}$ bimetallic materials have proven to be good models for traditionally prepared catalysts. $^{32}$

A comparison of the catalytic $\mathrm{CO}$ oxidation activity for $\mathrm{TiO}_{2}$-supported catalysts prepared with $\mathrm{G} 4-\mathrm{NH}_{2}-$ $\left(\mathrm{Pd}_{27.25} \mathrm{Au}_{27.25}\right), \mathrm{G} 4-\mathrm{NH}_{2}\left(\mathrm{Pd}_{55}\right)$, and G4-NH $\mathrm{NH}_{2}\left(\mathrm{Au}_{55}\right)$ is shown in Fig. $6 .{ }^{17}$ The onset temperature of catalytic activity $(1 \% \mathrm{CO}$ conversion) for the $\mathrm{PdAu}$ catalyst was $150{ }^{\circ} \mathrm{C}$, while the $\mathrm{Pd}$ and $\mathrm{Au}$ catalysts were inactive at this temperature. The complete $(100 \%) \mathrm{CO}$ conversion temperature for $\mathrm{PdAu}$ $\left(250{ }^{\circ} \mathrm{C}\right)$ was $35{ }^{\circ} \mathrm{C}$ lower than that of $\mathrm{Pd}\left(285^{\circ} \mathrm{C}\right)$, which also indicates a synergistic electronic ligand effect. Furthermore, it is worth noting that the Au-only supported catalysts exhibited no activity toward $\mathrm{CO}$ oxidation at temperatures $<300{ }^{\circ} \mathrm{C}$. Lifetime measurements of the $\mathrm{PdAu}$ catalysts indicated that the $100 \%$ CO oxidation activity was retained for $24 \mathrm{~h}$ and then the activity became $60-80 \%$ over a period of about two days, which was possibly due to coking. Chandler and co-workers ${ }^{32}$ reported a similar phenomenon in the catalytic $\mathrm{CO}$ oxidation activity using $\mathrm{SiO}_{2}$-supported $\mathrm{PtAu}$ catalysts prepared with $\mathrm{G} 5-\mathrm{OH}\left(\mathrm{Pt}_{16} \mathrm{Au}_{16}\right)$. $\mathrm{CO}$ oxidation catalysis by $\mathrm{Pt}_{16} \mathrm{Au}_{16}$ showed three distinct regions of activity. At low temperatures $\left(30-80{ }^{\circ} \mathrm{C}\right) \mathrm{Pt}_{32}$ showed little activity, but there was substantial activity (rate: $2.0-2.6 \mathrm{~mol} \mathrm{CO} / \mathrm{mol}$ $\mathrm{Pt} / \mathrm{min}$ ) for $\mathrm{Pt}_{16} \mathrm{Au}_{16}$, which was due either to $\mathrm{Au}$ or possibly to PtAu bimetallic sites on the catalyst. At temperatures of $120{ }^{\circ} \mathrm{C}$ or higher, $\mathrm{Pt}_{16} \mathrm{Au}_{16}$ exhibited a higher activity (rate: $>4.0 \mathrm{~mol} \mathrm{CO} / \mathrm{mol} \mathrm{Pt} / \mathrm{min}$ ), which was indistinguishable from $\mathrm{Pt}_{32}$, but $\mathrm{Au}_{32}$ showed a lower activity (rate: $0.5 \mathrm{~mol} \mathrm{CO} /$ $\mathrm{mol} \mathrm{Au} / \mathrm{min})$. This may be presumed to be because the surface Pt atoms were very active at these temperatures and therefore responsible for essentially all of the catalysis. In the intermediate temperature range $\left(80-120{ }^{\circ} \mathrm{C}\right.$, where $\mathrm{Pt}$ begins to become active), both metals or types of sites may be active. Au may be promoting $\mathrm{CO}$ oxidation catalysis by $\mathrm{Pt}$ at these temperature, possibly by breaking up Pt ensembles or

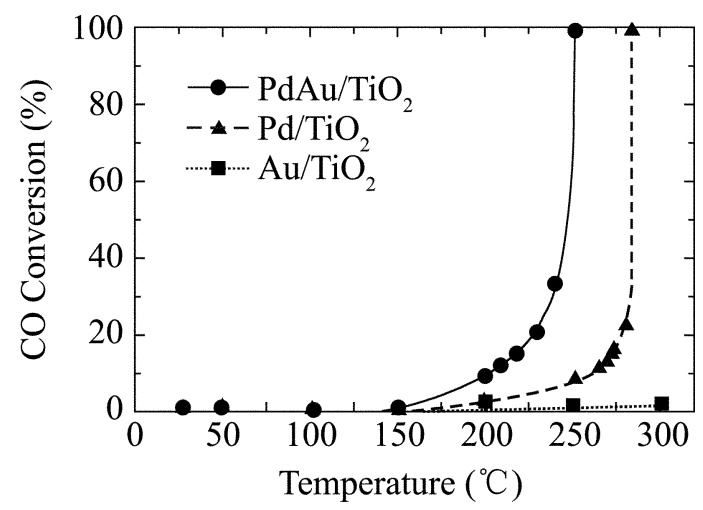

Fig. 6 Percentage $\mathrm{CO}$ oxidation as a function of temperature for $\mathrm{PdAu}$, Pd-only, and Au-only catalysts supported on $\mathrm{TiO}_{2}$. The catalysts were prepared using G4-NH $\mathrm{NH}_{2}\left(\mathrm{Pd}_{27.5} \mathrm{Au}_{27.5}\right), \mathrm{G} 4-\mathrm{NH}_{2}\left(\mathrm{Pd}_{55}\right)$, and $\mathrm{G} 4-\mathrm{NH}_{2}\left(\mathrm{Au}_{55}\right)$ DENs, respectively. Catalytic reactions were carried out using a 2:1 ratio of $\mathrm{O}_{2} / \mathrm{CO}$ and a gas hourly space velocity of $20000 \mathrm{~cm}^{3} \mathrm{~g}^{-1} \mathrm{~h}^{-1}$. Reprinted with permission from ref. 17 . Copyright 2005 American Chemical Society. alternatively by providing weak $\mathrm{CO}$ or $\mathrm{O}_{2}$ adsorption sites. ${ }^{46}$ The ability of $\mathrm{Pt}_{16} \mathrm{Au}_{16}$ to catalyze $\mathrm{CO}$ oxidation was at a rate of 8.5 times higher than that of the physical mixture of $\mathrm{Pt}_{32}$ and $\mathrm{Au}_{32}$ at $100{ }^{\circ} \mathrm{C}$. The $\mathrm{Pt}_{16} \mathrm{Au}_{16}$ catalyst was substantially highly resistant to particle agglomeration. The primary role of $\mathrm{Pt}$ was to help stabilize smaller particles. It is possible that $\mathrm{Pt}$ adds an additional functionality to the catalyst by not only binding $\mathrm{O}_{2}$ but also locating bound or activated $\mathrm{O}_{2}$ near active $\mathrm{Au}$ sites. When $\mathrm{CO}$ was less strongly bound to the surface, the $\mathrm{Pt}_{16} \mathrm{Au}_{16}$ catalytic behavior was best described by bimetallic nanoparticles in which $\mathrm{Au}$ sites were active at low temperatures and $\mathrm{Pt}$ sites took over at higher temperatures. $^{32}$

Chandler's work with PtAu system ${ }^{32}$ and Crooks's work with $\mathrm{PdAu}$ catalysts ${ }^{17}$ all reported catalytic synergism arising from the intimate mixing of two metals; however, both studies were limited to a single bimetallic particle composition. Furthermore, Chandler and co-workers extended this general preparative route for heterogeneous $\mathrm{Al}_{2} \mathrm{O}_{3}$-supported $\mathrm{PtCu}$ catalysts to the $\mathrm{PtCu}$ system and studied varying heterogeneous catalyst compositions using G5-OH DENs as catalyst precursors. ${ }^{44}$ The results showed that the incorporation of $\mathrm{Cu}$ into $\mathrm{Pt}$ nanoparticles had an opposing effect on $\mathrm{CO}$ oxidation and toluene hydrogenation catalysis. Toluene hydrogenation was suppressed by $\mathrm{Cu}$ addition, and at a $2: 1 \mathrm{Cu} / \mathrm{Pt}$ ratio, the catalysis was effectively shut off. This tuning of catalytic activity was likely due to surface enrichment in $\mathrm{Cu}$, which was inactive for toluene hydrogenation. However, incorporating $\mathrm{Cu}$ into the nanoparticles enhanced the catalysis of $\mathrm{CO}$ oxidation. This enhancement was consistent with the facile exchange of surface and subsurface atoms within individual nanoparticles, which can be interpreted in terms of a variety of potential structural and electronic influences. ${ }^{44}$

Well-defined PtPd bimetallic catalysts prepared using the G6-OH template can be used to correlate precisely the effect of catalyst composition with the efficiency of the oxygen reduction reaction (ORR) (Scheme 2). ${ }^{47}$ This is of great significance for two reasons. Firstly, dendrimer templating is the only method we are aware of for preparing very welldefined, electrocatalytically active bimetallic nanoparticles in the $<3 \mathrm{~nm}$ size range. Secondly, dendrimer-encapsulated catalysts can be characterized prior to electrode immobilization using methods such as TEM and EDS. This ensures that catalytic performance is not dominated by a small number of unique particles, which in turn makes it possible to directly correlate the elemental composition of the particles to their catalytic function. The PtPd bimetallic DENs were coupled onto glassy carbon electrode (GCE) by an electrooxidation reaction in an aqueous $0.1 \mathrm{M} \mathrm{LiClO}_{4}$ electrolyte solution. The electrodes modified with these PtPd bimetallic DENs were confirmed as being electrocatalytically active for four-electron oxygen reduction. The electrocatalytic processes characterized by cyclic and rotating disk voltammetry indicated that PtPd bimetallic DENs exhibited relative mass activity enhancements for ORR of up to a factor of 2.4 compared to monometallic Pt DENs.

Electrodeposition is usually used for the preparation of metal nanostructures on surfaces. Qian and Yang ${ }^{48}$ reported 


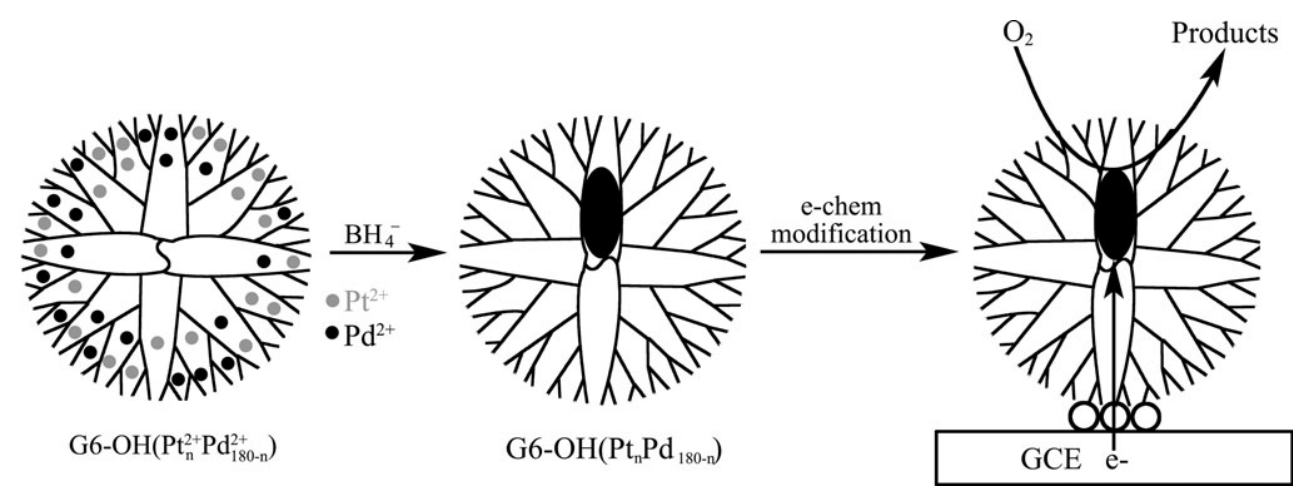

Scheme 2 Electrocatalytic $\mathrm{O}_{2}$ reduction at glassy carbon electrodes (GCEs) modified with PdPt DENs.

the G4- $\mathrm{NH}_{2}$ PAMAM dendrimer-assisted electrodeposition of AuPt bimetallic nanoflowers in a $0.5 \mathrm{M} \mathrm{H}_{2} \mathrm{SO}_{4}$ supporting electrolyte solution. The AuPt nanoflowers contained two parts: the 'light' part and the 'pale' part. The two parts consisted of many small bimetallic nanoparticles, which were attributed to the progressive nucleation process. Moreover, the 'light' part contained more bimetallic nanoparticles. Morphologies of AuPt bimetallic nanoparticles can affect their catalytic activities, which are different from those of individual nanoparticles. ${ }^{32}$ The AuPt morphologies depended on the electron deposition time, potential, and the layer number of assembled dendrimers. The size of nanoflowers increased as the deposition time was extended. With more layers of dendrimers assembled on the surface, the 'pale' part became bigger and more obvious. Cyclic voltammetric experiments showed that the electrochemical properties of nanoflowers deposited on the indium tin oxide (ITO) electrode surface were similar to those of bare Au and Pt electrodes, indicating that the deposited nanoflowers consisted of bimetallic nanoparticles. The bimetallic nanoflowers also exhibited significant electrocatalytic activity toward oxygen reduction. This is because the surface of the deposited bimetallic nanoparticles was rough and exhibited a flower structure, and the high surface area-to-volume of the deposited bimetallic nanoparticles led to the good electrocatalytic activity toward oxygen reduction. ${ }^{48}$

In a summary, the major applications of bimetallic DENs are also outlined in Table 2. It can be anticipated that DENs will find more extensive applications in various reaction systems.

\section{Conclusions and prospects}

The synthesis and catalytic application of bimetallic DENs are developing continuously, thanks to the efforts of many pioneers and the advent of modern characterization techniques. In general, the monodispersed stable bimetallic DENs can be synthesized by three different methods. The co-complexation route leads to alloy-type bimetallic DENs, and both the sequential loading and partial displacement methods can lead to alloy or core/shell DENs, depending on the identities of the two metals and the procedures of the synthesis operations. In addition, the ' $\mathrm{Cu}$ exchange' method has been confirmed properly for the preparation of PtAu bimetallic DENs.
Besides EXAFS measurement and ATR-IR analysis of CO adsorption, the selective extraction strategy provided a new tool for analyzing the composition of the core/shell bimetallic nanaoparticles in the range of around $2 \mathrm{~nm}$ in size. The results suggested that there were significant differences in the catalytic activities for metal DENs of different structures: the catalysts of bimetallic nanoparticles via dendrimer-encapsulated preparation were often improved in performance over those of monometallic nanoparticle catalysts prepared by the same method, which should be due to the synergistic electronic effect. Steric crowding may sometimes result in positive dendritic effects on selectivity, although it may restrict the applications of DENs in catalyzing larger substrates. In most cases, however, what is hoped for is an efficiency in terms of turnover rates, yields, and stereoselectivities which is very close to that of the parent, non-dendritic analogous catalysts. So, the research in catalysis using bimetallic DENs has been expanding, and there is also a noteworthy trend toward supported or heterogeneous dendritic catalysts. The invention of strategies for recycling homogeneous catalysts is still an important challenge. Metal DENs could exert an important role because they may be easily recovered and recycled. Three methods can be used to aid in the removal of these nanoparticle catalysts: nanofiltration, ${ }^{49}$ biphase catalysis, ${ }^{50}$ and phase transfer. ${ }^{51}$

In the future it may be possible to synthesize bimetallic nanoparticles of particular structures based on a first-principles understanding of catalytic selectivity. Although dendrimers are relatively expensive compared with other commercial catalysts, which may affect their industrial applications, the bimetallic DENs can still be used as model systems to study structure-function relationships because of their high degree of uniformity and easily controllable structure. In addition to catalysis, bimetallic DENs may also be applied in other fields, such as luminescent materials for biological labels ${ }^{52}$ and magnetic materials for data storage, etc. ${ }^{53}$

\section{Acknowledgements}

We thank the financial supports from the Science Funding of Guangdong Province of China (project No. B40502) and the China Scholarship Fund. 


\section{References}

1. R. Andrés, E. de Jesús and J. C. Flores, New J. Chem., 2007, 31, 1161-1191.

2. D. A. Tomalia, A. M. Naylor and W. A. Goddard III, Angew. Chem., Int. Ed. Engl., 1990, 29, 138-175.

3. G. Li and Y. Luo, Inorg. Chem., 2008, 47, 360-364.

4. D. Astruc and F. Chardac, Chem. Rev., 2001, 101, 2991-3023.

5. C. Kojima, K. Kono, K. Maruyama and T. Takagishi, Bioconjugate Chem., 2000, 11, 910-917.

6. A. Adronov and J. M. J. Fréchet, Chem. Commun., 2000, 18, 1701-1710.

7. M. W. P. L. Baars and E. W. Meijer, Top. Curr. Chem., 2000, 210, $131-182$.

8. X.-C. Peng, X.-H. Peng and J.-Q. Zhao, J. Appl. Polym. Sci., 2007, 106, 3468-3473.

9. O. A. Matthews, A. N. Shipway and J. F. Stoddart, Prog. Polym. Sci., 1998, 23, 1-56.

10. Y.-M. Chung and H.-K. Rhee, J. Colloid Interface Sci., 2004, 271, 131-135.

11. C. Wang, G. Zhu, J. Li, X. Cai, Y. Wei, D. Zhang and S. Qiu, Chem.-Eur. J., 2005, 11, 4975-4982.

12. T. Endo, T. Kuno, T. Yoshimura and K. Esumi, J. Nanosci. Nanotechnol., 2005, 5, 1875-1882.

13. Y. Niu, L. Sun and R. M. Crooks, Macromolecules, 2003, 36, $5725-5731$.

14. Y.-M. Chung and H.-K. Rhee, Catal. Surv. Asia, 2004, 8, 211-223.

15. R. W. J. Scott, A. K. Datye and R. M. Crooks, J. Am. Chem. Soc., 2003, 125, 3708-3709.

16. R. W. J. Scott, O. M. Wilson, S.-K. Oh, E. A. Kenik and R. M. Crooks, J. Am. Chem. Soc., 2004, 126, 15583-15591.

17. R. W. J. Scott, C. Sivadinarayana, O. M. Wilson, Z. Yan, D. W. Goodman and R. M. Crooks, J. Am. Chem. Soc., 2005, 127, 1380-1381.

18. R. M. Crooks, M. Zhao, L. Sun, V. Chechik and L. K. Yeung, Acc. Chem. Res., 2001, 34, 181-190.

19. J. H. Sinfelt, Acc. Chem. Res., 1977, 10, 15-20.

20. M. Harada, K. Asakura and N. Toshima, J. Phys. Chem., 1993, 97, 5103-5114.

21. Y. Niu and R. M. Crooks, C. R. Chim., 2003, 6, 1049-1059.

22. J. H. Sinfelt, Acc. Chem. Res., 1987, 20, 134-139.

23. Y.-M. Chung and H.-K. Rhee, Catal. Lett., 2003, 85, 159-164.

24. M. Zhao and R. M. Crooks, Angew. Chem., Int. Ed., 1999, 38, 364-366.

25. X.-C. Peng, PhD Dissertation: Synthesis and Application of Modified Poly (amidoamine) Dendrimer, South China University of Technology, Guangzhou, China, 2007, Call\# 1011-D2007-1, http://www.scut.edu.cn/202.38.232.1/bslw.jsp.

26. D. Liu, J. Monnier and C. T. Williams, in AIChE Annual Meeting (Conference Proceedings), American Institute of Chemical Engineers, New York, 2005, p. 11602.

27. Y.-M. Chung and H.-K. Rhee, J. Mol. Catal. A: Chem., 2003, 206, 291-298.
28. O. M. Wilson, R. W. J. Scott, J. C. Garcia-Martinez and R. M. Crooks, J. Am. Chem. Soc., 2005, 127, 1015-1024.

29. M.-C. Daniel and D. Astruc, Chem. Rev., 2004, 104, 293-346 and references mentioned therein.

30. H. Xie, C. T. Williams and H. J. Ploehn, in AIChE Annual Meeting (Conference Proceedings), American Institute of Chemical Engineers, New York, 2005, p. 11581.

31. R. W. J. Scott, O. M. Wilson and R. M. Crooks, J. Phys. Chem. B, 2005, 109, 692-704.

32. H. Lang, S. Maldonado, K. J. Stevenson and B. D. Chandler, J. Am. Chem. Soc., 2004, 126, 12949-12956.

33. R. West, Y. Wang and T. Goodson III, J. Phys. Chem. B, 2003, 107, 3419-3426.

34. M. Zhao and R. M. Crooks, Chem. Mater., 1999, 11, 3379-3385.

35. D. S. Deutsch, A. Siani, O. Alexeev, C. T. Williams and M. D. Amiridis, in AIChE Annual Meeting (Conference Proceedings), American Institute of Chemical Engineers, New York, 2005, p. 10328.

36. Y. Gu, H. Xie, J. Gao, D. Liu, C. T. Williams, C. J. Murphy and H. J. Ploehn, Langmuir, 2005, 21, 3122-3131.

37. B.-J. Hwang, L. S. Sarma, J.-M. Chen, C.-H. Chen, S.-C. Shih, G.-R. Wang, D.-G. Liu, J.-F. Lee and M.-T. Tang, J. Am. Chem. Soc., 2005, 127, 11140-11145.

38. O. M. Wilson, R. W. J. Scott, J. C. Garcia-Martinez and R. M. Crooks, Chem. Mater., 2004, 16, 4202-4204.

39. N. Toshima, T. Yonezawa and K. Kushihashi, J. Chem. Soc., Faraday Trans., 1993, 89, 2537-2543.

40. Y. Mizukoshi, T. Fujimoto, Y. Nagata, R. Oshima and Y. Maeda, J. Phys. Chem. B, 2000, 104, 6028-6032.

41. L. K. Yeung and R. M. Crooks, Nano Lett., 2001, 1, 14-17.

42. N. Toshima and T. Yonezawa, New J. Chem., 1998, 22, 1179-1201

43. J. K. Vohs and B. D. Fahlman, New J. Chem., 2007, 31, 1041-1051.

44. N. N. Hoover, B. J. Auten and B. D. Chandler, J. Phys. Chem. B, 2006, 110, 8606-8612.

45. D. S. Deutsch, A. Siani, P. T. Fanson, H. Hirata, S. Matsumoto, C. T. Williams and M. D. Amiridis, J. Phys. Chem. C, 2007, 111, 4246-4255.

46. A. Bourane and D. Bianchi, J. Catal., 2004, 222, 499-510.

47. H. Ye and R. M. Crooks, J. Am. Chem. Soc., 2007, 129, $3627-3633$.

48. L. Qian and X. Yang, J. Phys. Chem. B, 2006, 110, 16672-16678.

49. D. de Groot, B. F. M. de Waal, J. N. H. Reek, A. P. H J. Schenning, P. C. J. Kamer, E. W. Meijer and P. W. N. M. van Leeuwen, J. Am. Chem. Soc., 2001, 123, 8453-8458.

50. A. Gong, Q. Fan, Y. Chen, H. Liu, C. Chen and F. Xi, J. Mol. Catal. A: Chem., 2000, 159, 225-232.

51. V. Chechik, M. Zhao and R. M. Crooks, J. Am. Chem. Soc., 1999, 121, 4910-4911.

52. B. I. Lemon and R. M. Crooks, J. Am. Chem. Soc., 2000, 122, 12886-12887.

53. I. M. L. Billas, A. Châtelain and W. A. de Heer, Science, 1994, 265, 1682-1684. 